\title{
Cloud-based System for Agro-Extension Services towards Combating Food Insecurity in Africa
}

\author{
Olufunso Dayo Alowolodu \\ School of Computing, \\ Federal University of Technology, \\ Akure, Nigeria
}

\author{
Arome Junior Gabriel \\ School of Computing, \\ Federal University of Technology, \\ Akure, Nigeria
}

\begin{abstract}
Food security is one of the most fundamental requirement for the continual survival of mankind. The United Nations as well as Commonwealth of Nations have accordingly given so much attention to food security especially in recent times. Extension services offered by agricultural authorities helps to disseminate to farmers news, practices and equipment necessary for improving their periodic yield or productivity. Agricultural extension programme improves welfare through an increase in farmers' income. Unfortunately, in recent times, these services have been hampered by the various forms of unrest such as terrorism, kidnappings, banditry, and even outbreak of infectious diseases such as Ebola or even the most recent outbreak, COVID-19. As a result of concerns like these, there is recently an upsurge in the number of services that have been moved online as against the traditional method. Furthermore, the lack of adequate storage space for the massively generated agricultural information in today's modern electronic society is a huge problem that requires attention. This paper proposes an efficient cloud computing and mobile technology based agro-extension services system for use by extension services providers or officials. This will bring a lot of ease to extension services as well as go a long way in guaranteeing the safety and willingness of their agents to continue in rendering extension services required for effective farming.
\end{abstract}

\section{General Terms}

Agriculture, Cloud Computing, Communication, Food

\section{Keywords}

Food Security, Cloud Computing, Information Security, Agro-extension

\section{INTRODUCTION}

Food security according to the United Nations' Committee on World Food Security is defined as a situation that all people, at all times, have physical, social, and economic access to sufficient, safe, and nutritious food that meets their food preferences and dietary needs for an active and healthy life [1]. Indeed, enhancing hunger reduction and food security is one of the world's Millennium Development Goals (MDGs). In recent times, food insecurity and rapid increase in hunger has become an item of major concern across the world, especially in troubled regions and poverty-ravished nations. Food Insecurity could occur either naturally (famine, earthquake, flood, land slide, hurricane and so on) or via manmade occurrences such as (insurgences, wars, banditry, terrorism). Today in Nigeria, the shortage of food items, and hence, the corresponding rapid increase in the prices of food items can to a great extent be traced to the activities of terrorist and bandits, especially in Northern-Nigeria.

Terrorism has become a global issue that is wreaking havoc on all the sectors of the global economy. One of the areas most affected is food security. This act of terrorism has decimated many communities, destroyed food crops, killed cattle and forced farmers to flee to protective camps, often making many rely on food aids from international organizations. Markets are getting closed down and custom duties have dwindled [2]. In the midst of these chaos, insurgents have seized cattle and harvested or destroyed crops in anger and frustration. Refugees in the camps are insecure and cannot cultivate crops in the due season. Relief agencies have grappled with food scarcity as the number of refugees in the camps swell. Such a chaotic situation has compounded food crises, which is already a serious problem in Africa. People have fled from one settled area to another for security and the tactics employed by the terrorists have not been environmental friendly. This has seriously affected food and cash crop production in places that were majorly into agriculture. Unfortunately, most of the food needed in Nigeria is produced by peasant farmers who lack capital, skills, expertise, energy and other viable materials to produce in large quantity that will meet the requirement of the growing population. Also, the use of modern technologies in the production and distribution of agricultural production is very low in Nigeria. As a result, the sector depends more on manual labor for farm activities. Thus, food insecurity in Nigeria is a recurrent and double-digit problem [3].

A fundamental way to ensure national food security is to convert the achievements in scientific research into productive forces and the key lies in innovating grass-root agro-technical extension. The use of Cloud Computing technology in agricultural areas has greater chance in the overall development of the economy through agricultural modernization and agricultural information in extension services [4]. Cloud database can be used to store and share the crop information, prices of the fertilizers and crops. It gives information to the farmer and when used as an information database, it saves extension officers from the dangers of moving about from state to state to disseminate information during insurgency.

To aid farmers in diverse areas of agriculture, lots of information needs to be delivered to them for high agricultural production through Agriculture Information system, which can provide a dynamic and reliable environment that will guarantees quality service. A Cloud based system will improve extension service by providing mass data storage and dynamic expansion in the extension information system as 
Cloud storage is a scalable and highly reliable storage mode which supports mass data storage and resource dynamic expansion. For these to be achieved, there is the need to develop a system for extension workers use in the dissemination of information. Such system addresses problems pointed out in some existing research works and offers the advantages of easy access to current and up-to-date information at optimal time. A well-developed system for extension services could eliminate problems that pertains to insufficient extension workers and also reduce insecurity of extension workers during insurgency by disseminating information through bulk sms to the rural farmers.

In [6], the authors opined that fewer resources and lower efficiency are big problems in the agro-technical extension information system. To meet the requirements of mass data storage and dynamic expansion in the agro-technical extension information system, Cloud storage technology which is a scalable and highly reliable storage mode, supporting mass data storage and resource dynamic expansion is hereby proposed.

\section{ROLE OF EXTENSION SERVICES IN AGRICULTURE}

Many developing economies like the ones we have in SubSaharan Africa, are partly or wholly dependent on agriculture. The vision of such economies must be to greatly increase agricultural productivity in such a manner that will guarantee improvement in food security and massive reduction in poverty/hunger. Such a vision is in tandem with the Millennium Development Goals (MDGs) of reducing hunger and to promoting food security.

Sadly, more often than not, it has been noticed that, the current level of agricultural productivity have not been able to meet up with this fundamental MDG. A large portion of the agrarian population are still poor, the hunger level is far from being reduced [7].

Achieving the MDG's target productivity level as far as the food production or agriculture sector is concerned, will require carefully built structures or mechanisms for the development and dissemination of improved agricultural technologies to farmers, especially those in the rural areas. Indeed, inadequate extension services have been recognized as a major stumbling block to the growth of agriculture and the overall development of the rural communities as well as agro-dependent economies [8].

Governments of developing nations must invest so much in building the capacities of farmers through agricultural extension programmes. Indeed, a number of international and local funding agencies, non-governmental organizations and financial institutions have and continue to make investments in the delivery of extension services to farmers.

The impact of agricultural extension services or programmes in agricultural production cannot be overemphasized. It has been a major approach to ensuring minimization or even outright elimination of rural poverty and food insecurity. Amongst many, agricultural extension is crucial to technology transfer, support rural adult learning, support farmers to solve problems, as well as helping them get involved in agricultural knowledge and information system [9]. By way of definition, "extension" refers to structures or mechanisms that ameliorates agriculture stakeholders' access to knowledge, information and technologies. Such mechanisms simplifies farmers' collaboration with allies in agribusiness, education and even research. Furthermore, extension helps farmers build their own technical know-how, and other management expertise [10]. Extension is therefore fundamental to efficient/effective agricultural production. Development of a nation or a group of people can to a great extent be precipitated on agricultural extension, since it is one major backbone of agricultural and rural development [11].

In fact, some researchers claimed that, extension offers information on new technologies for agricultural communities. These information greatly enhances agricultural production, profits and ultimately, the populace's standard of living [11]. Extension service providers directly and sometimes indirectly offers several services to farmers and marketers alike. Some of these services includes; bringing new innovations to the notice of farmers, demonstrating new technologies to farmers, refining skills and knowledge for production/processing, identifying farmers' problems towards additional research and decision-making, helping with access to markets and trade, collaborating with farmers towards ensuring proper management of natural resources, consolidating agricultural production groups, and even overall development of human/social aspects of communities. In a nutshell extension services [agents tends to offer solutions to common problems and queries of farmers [12][13][14].

\section{REVIEW OF RELATED WORKS}

Agriculture is a vital and relevant factor in a nation's economy and growth. It has greatly been a pillar of support in feeding the nation and generating revenue for the economy. Farmers who are responsible for planting crops and rearing animals are limited in knowledge and cannot alone meet up with the ever-growing demand and supply of food production and consumption in the nation. The farmers are sometimes short of adequate knowledge to improve agriculture and this has necessitated providing farmers with relevant information. This consequently, brought about agricultural extension which is an informal educational process directed toward the rural population which offers advice and information to help them solve their problems [10]. The use of Information and Communication Technology to improve information flow and to connect people within the rural areas has proved that illiteracy of farming communities may no longer be an excuse to deny some form of extension system. Effective communication of agricultural information to farmers is crucial in achieving optimum efficiency in agricultural extension administration and practice in Nigeria.

In [14], a participatory action research method was adopted for developing innovative communication pathways for disseminating agricultural information, agricultural knowledge and proven agricultural technologies from either extension agents or agricultural research centers or universities to farmers. The Web-based farmer's advisory information system catered for e-learning, while the Mobilebased farmers' advisory information system catered for $\mathrm{m}$ learning. A farmer or other stakeholders can access the system using either SMS or e-mail. A farmer also can ask any unstructured question by writing an SMS to the mobile number. Users can request specific information since they are communicating with an expert. 
In [15], farmer's access to different sources of knowledge as well as ICT was investigated through a comparative assessment between peri-urban and rural settings, and discovered that setting and information needs are the major influences on sources used. Farmers continuously gather new information to keep up with the emerging trends and technologies, and they also store and share this knowledge. Despite the huge emphasis placed on the need to use ICTs to facilitate information access among smallholder farmers, the adoption levels of these technologies is still very low. This is largely due to lack of information about the existence of such technologies.

The work in [6] designed an agro-technical extension information system based on Cloud storage. It was noticed that fewer resources and reduced efficiency were big problems in the agro-technical extension information system. The traditional storage solutions faced some difficulties due to mass data storage and resources dynamically expanding. To curb this in the agro-technical extension activities and to meet the requirements of mass data storage, dynamic expansion and resource conservation in the agro-technical extension information system, Cloud storage technology was introduced to store data. From the adoption of Cloud storage technology, conclusion was drawn that data storage capacity of information systems can be greatly improved, data security is guaranteed since there are multiple copies of data store and the stability of the system is improved as the interface layer is adopted.

The authors of [16] examined the public extension service through interpretation of data collected from 1104 extension workers in Turkey. This study investigated the linkages, integration and compatibility levels of extension in Turkish AKIS, and defines the bottlenecks in the system. The components of the AKIS such as factors affecting extension performance, information sources, extension methods, actor effectiveness and compatibility were used in the multidimensional scaling (MDS) analysis. The important weaknesses of the Turkish AKIS can be summarized as low occupational satisfaction and motivation levels of the extension workers, Social and political pressures during the extension activities, Limited farmer visits, extension activities mostly focus on yield and production increases but, limited efforts are provided for capacity building and empowering the local actors in rural areas.

The paper in [4] opined that the Use of Cloud computing technology in agricultural areas has greater chance in the overall development of India. An effective implementation of Cloud computing is encouraging in agricultural sector. Cloud computing provides a shared pool of configurable IT resources on demand, as a scalable and elastic service, through a networked infrastructure, on a measured (pay-peruse or subscription) basis, which needs minimal management effort. The benefits discovered include Improved economic condition of the Nation, enhanced GDP of the nation, ensured food security level, Motivation of farmers and researchers, Data availability at any time and at any location without delay, Improved market price of Food, seeds, other product while the challenges are summarized as Maintenance \& Supervision by third party, So data security is less, Indirect administrator accountability, Less physical control, attraction to hackers and requirement of constant Internet connection.
The work in [17] opined that future of farming is in the Cloud. This was borne out of the fact that farmers could take back controls that had been given to the forces of nature like seasons, the climate patterns and the precipitation level through the help of technology particularly the Cloud. This is because the plethora of information that is being gathered on the soil within fields, the plants growing on the field, the weather and so on could be uploaded to the Cloud. Timely processing of the data allow farmers to act within a growing season and correct problems before they become unfavorable to products.

In [18], it was observed that agriculture had been stuck with traditional methods and ideas for so long and it is high time to embrace the newest technological revolutions that is sweeping across the various economies of the world which is Cloud Computing. Agriculture in Cloud Computing offered multiple avenues for growth and prosperity as it allows the company to focus on the core areas of the business rather than investing in additional computer infrastructures because all computing resources needed are being provisioned in the Cloud.

\section{THE PROPOSED SYSTEM}

The proposed system design involves developing a Cloud database for information management for agricultural Extension workers and farmers. The architecture of the proposed system is as presented in Figure 1.

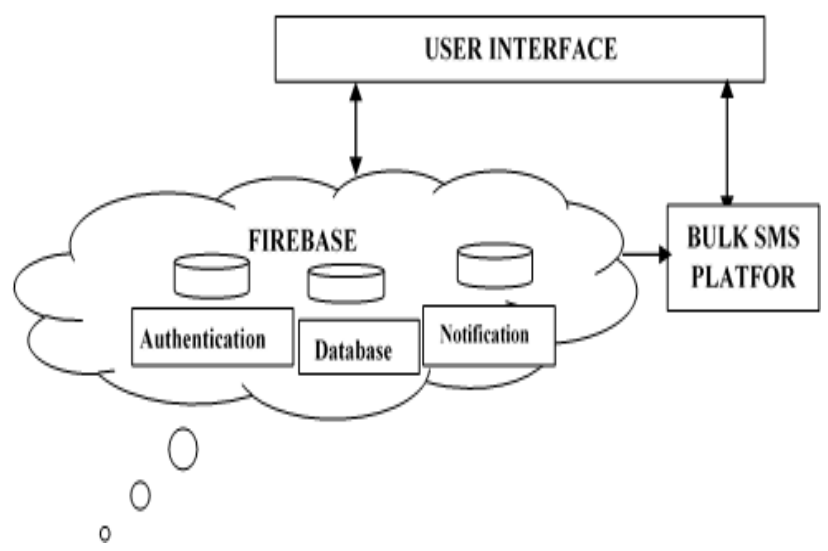

Figure 1: Proposed System Architecture

The system architecture depicts a Cloud based environment which aids provision and dissemination of information to extension workers. The diagram below shows the user interface interacting with the database in the Cloud. Firebase provides real time database, backend as a service, authentication and storage for the system. This basically aligns with the concept of Database-as-a Service and provides real time storage and hosting on the Cloud.

The extension worker logs in to the system and accesses relevant information from the database in the Cloud. The user then shares necessary information to the rural farmers using the bulk sms platform. The admin is the key actor of the system that posts news and information regularly. The admin's view is different from the extension worker's view.

An extension officer is expected to supply login details each time he/she wants to access the platform. Once the supplied login credentials are confirmed correct by the system, access is granted such extension officer. The extension officer can carry out variety of activities on the system. He/she can view 
relevant news, read, and comment and like news. The news update is done automatically using the reload function. The extension worker can also purchase bulk sms from the platform, for the purpose of disseminating messages to farmers under his supervision. A system administrator control the web application details such as news and information about users. The administrator can also read and reply messages.

The Newsfeed allows the user to view all the agricultural information available on the system and interact with other extension workers as well as the posts. The system will display all information on a news feed in chronological order with options to like, comment or share a post to other social media platforms.

The system designed will be able to stay up and running at least $98 \%$ of the time. Any downtime would be due to maintenance or upgrades. The system will refresh new information automatically on the news feed. The system will be able to serve up to thousands of users concurrently without crashing, with an interface that can easily be used and understood. The developed system will have to deal with large quantities of data and a large number of users accessing the data at once. Uploads and downloads are robust restarting where they stopped regardless of network quality, saving AgroExtension users time and bandwidth

The first page of the proposed agro-extension services system is as shown in Figure 2. It serves as the homepage, and registration channel for the user to register and be able to access the system's functionalities. Through the homepage, an existing user or even a new user can also learn more information about the system's benefits and functionalities and the organization as a whole.

In order to register on the platform, a new user clicks on the 'Register' button at the top right corner of the homepage. This action takes him to the registration page shown in Figure 3. The information required here includes; the username, full name, phone number, gender, e-mail address, as well as a chosen password for authentication purposes. Once the user hits the 'Proceed' button, the inputs are validated and the user is taken to his profile page or newsfeed page as the case may be.

In the case where an existing user who logs in is determined to be the administrator (based on his login credentials), then, he is taken to the system administrators' page. An administrator has higher privileges than a normal extension worker. As such, the administrator can carry out more activities on the platform than an extension worker.

\section{Welcome to AgroExtensions}

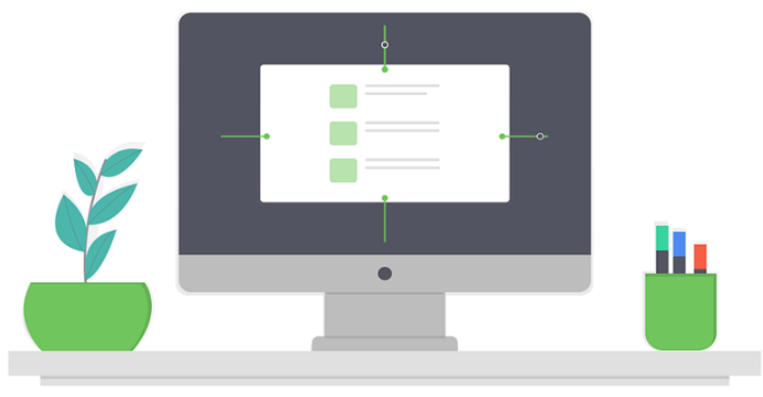

Figure 2: The homepage of the proposed Agro-Extension System

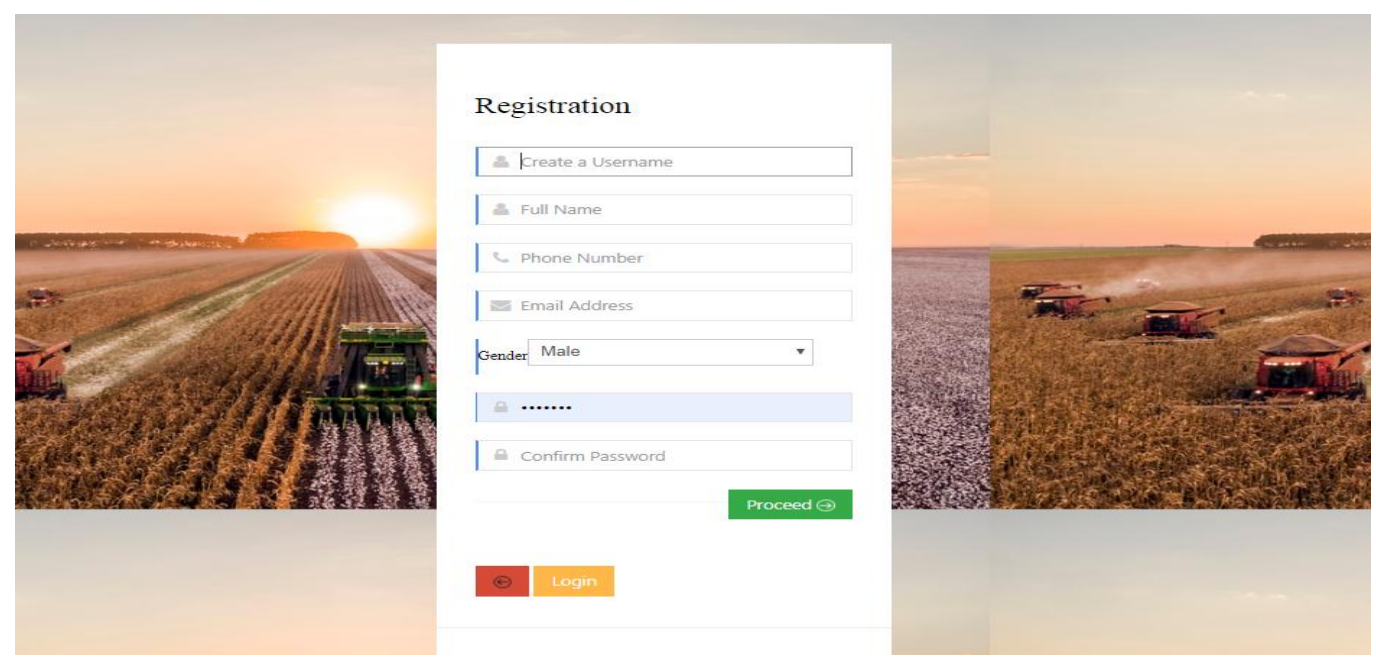

Figure 3: The New User Registration Page 


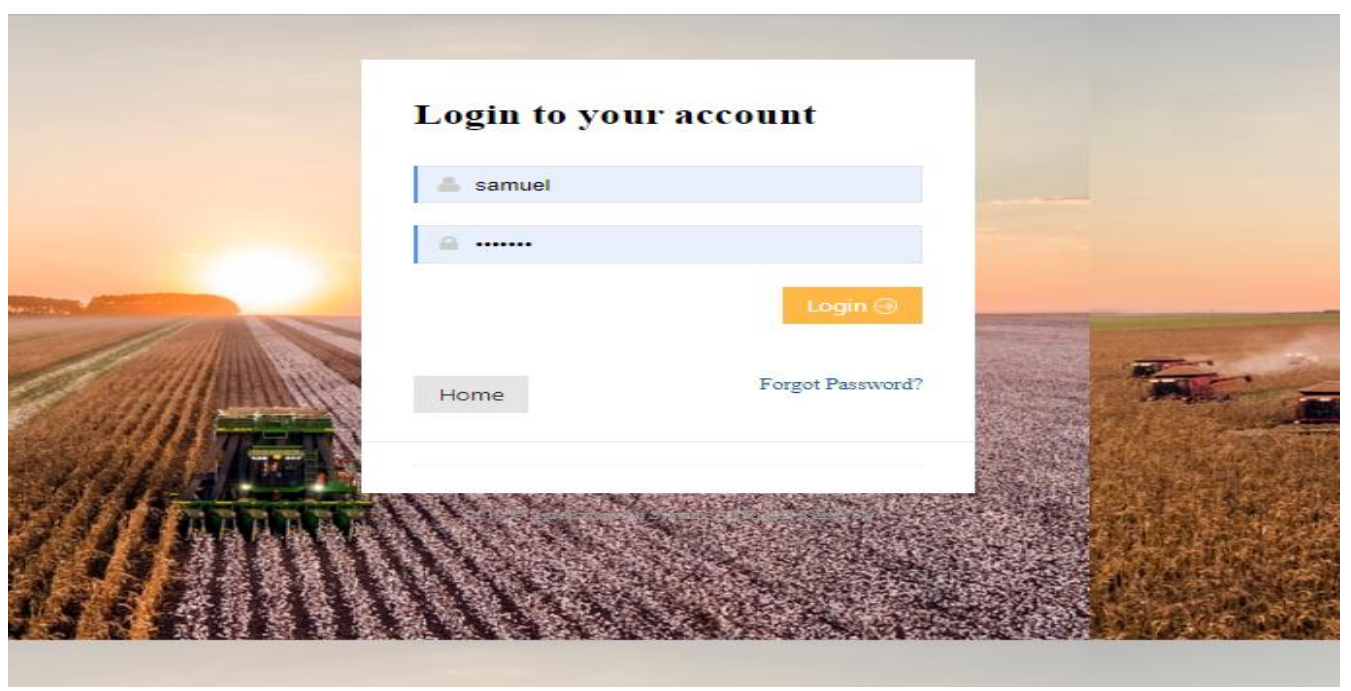

Figure 4: The existing users' login page

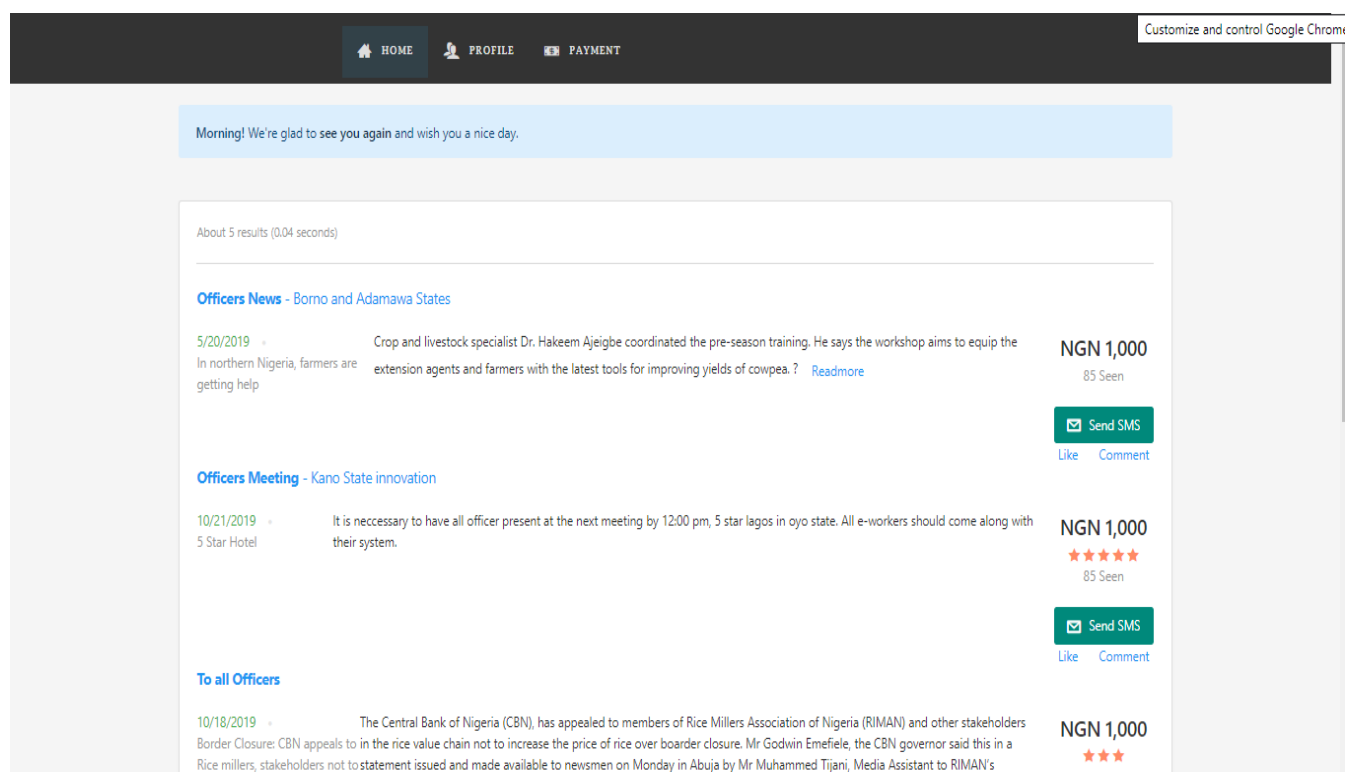

Figure 5: The newsfeed page

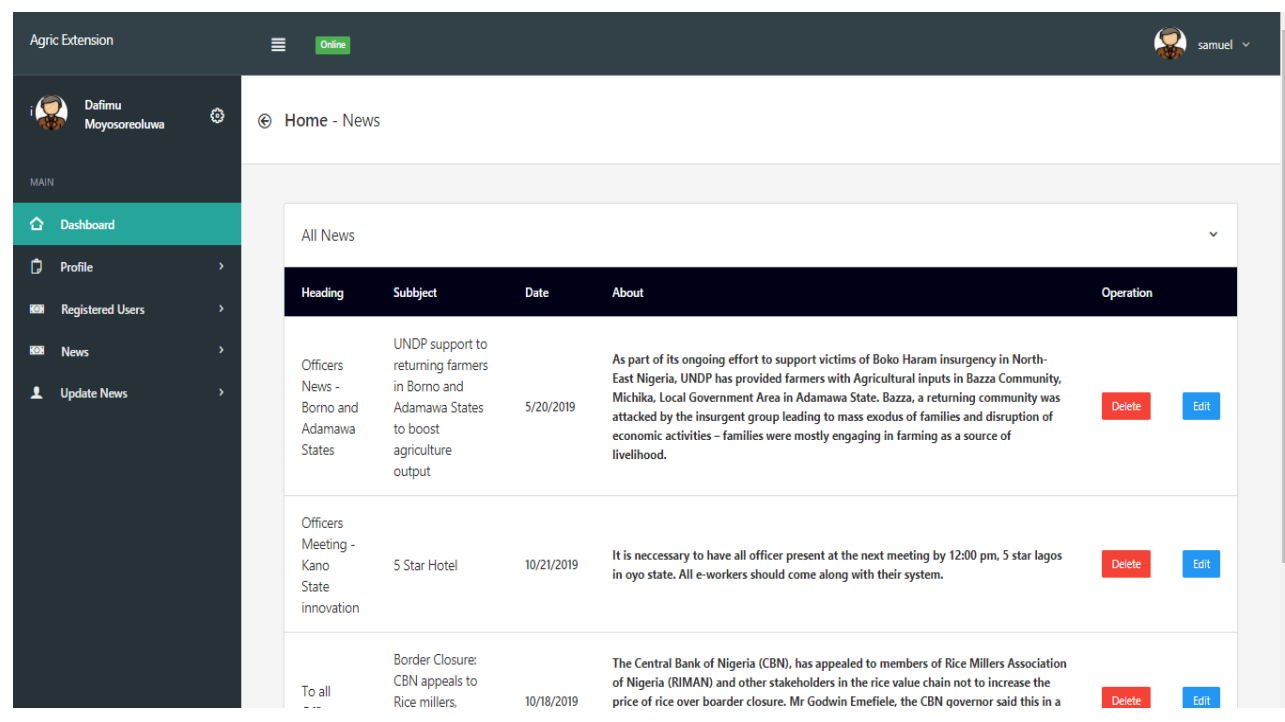

Figure 6: The System Administrator' page 


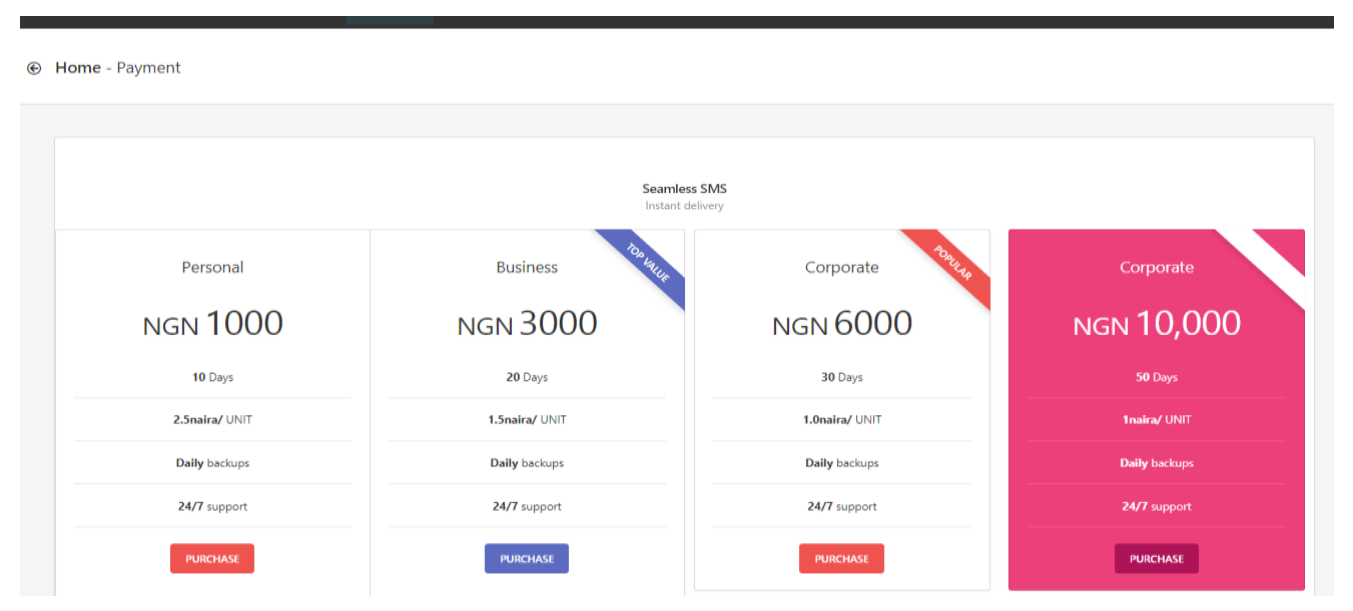

Figure 7: The Bulk SMS page

\subsection{Evaluation of the Proposed System}

In order to evaluate our proposed system, well-structured questionnaires were designed and administered to acquire responses of users of the system. About twenty (25) users within and around Akure, Nigeria, were quizzed, on their feel about the proposed system.

The questionnaires administered is made up of 12 questions and five point scaled variables; Strongly Agree, Agree, Fairly Agree, Indifferent, and Don't Agree were used.
Questions were asked about accuracy, importance of context in recommendation, friendliness to the user, correctness, understandability and acceptability of the system. Results obtained are plotted in graphs as shown in figures 4 and 5 .

Tables 3 shows the responses obtained from the users, while the analysis of the response is shown in Figure 4.

Table 3: Result of questionnaire from users

\begin{tabular}{|c|c|c|c|c|c|c|}
\hline $\mathbf{S} / \mathbf{N}$ & Metrics & SA & $\mathbf{A}$ & FA & IND & DA \\
\hline 1 & Results matched my interests & 9 & 14 & 1 & 1 & 0 \\
\hline 2 & $\begin{array}{l}\text { I found the system flexible to } \\
\text { use. }\end{array}$ & 17 & 6 & 2 & 0 & 0 \\
\hline 3 & The interface is user -friendly & 17 & 7 & 1 & 0 & 0 \\
\hline 4 & $\begin{array}{l}\text { The system speed is } \\
\text { acceptable. }\end{array}$ & 15 & 5 & 4 & 1 & 0 \\
\hline 5 & The system is quite easy to use & 15 & 7 & 3 & 0 & 0 \\
\hline 6 & $\begin{array}{l}\text { The system's accuracy is high } \\
\text { and acceptable }\end{array}$ & 13 & 8 & 2 & 2 & 0 \\
\hline 8 & $\begin{array}{l}\text { Overall, I am satisfied with the } \\
\text { system }\end{array}$ & 8 & 8 & 7 & 2 & 0 \\
\hline 9 & $\begin{array}{l}\text { It is true that cloud computing } \\
\text { is an essential part of agro- } \\
\text { extension services }\end{array}$ & 14 & 6 & 2 & 3 & 0 \\
\hline 10 & $\begin{array}{l}\text { The system can be } \\
\text { recommended to } \\
\text { stakeholders for use. }\end{array}$ & 15 & 7 & 3 & 0 & 0 \\
\hline 11 & $\begin{array}{l}\text { I will love to use this system } \\
\text { again }\end{array}$ & 16 & 7 & 1 & 1 & 0 \\
\hline
\end{tabular}




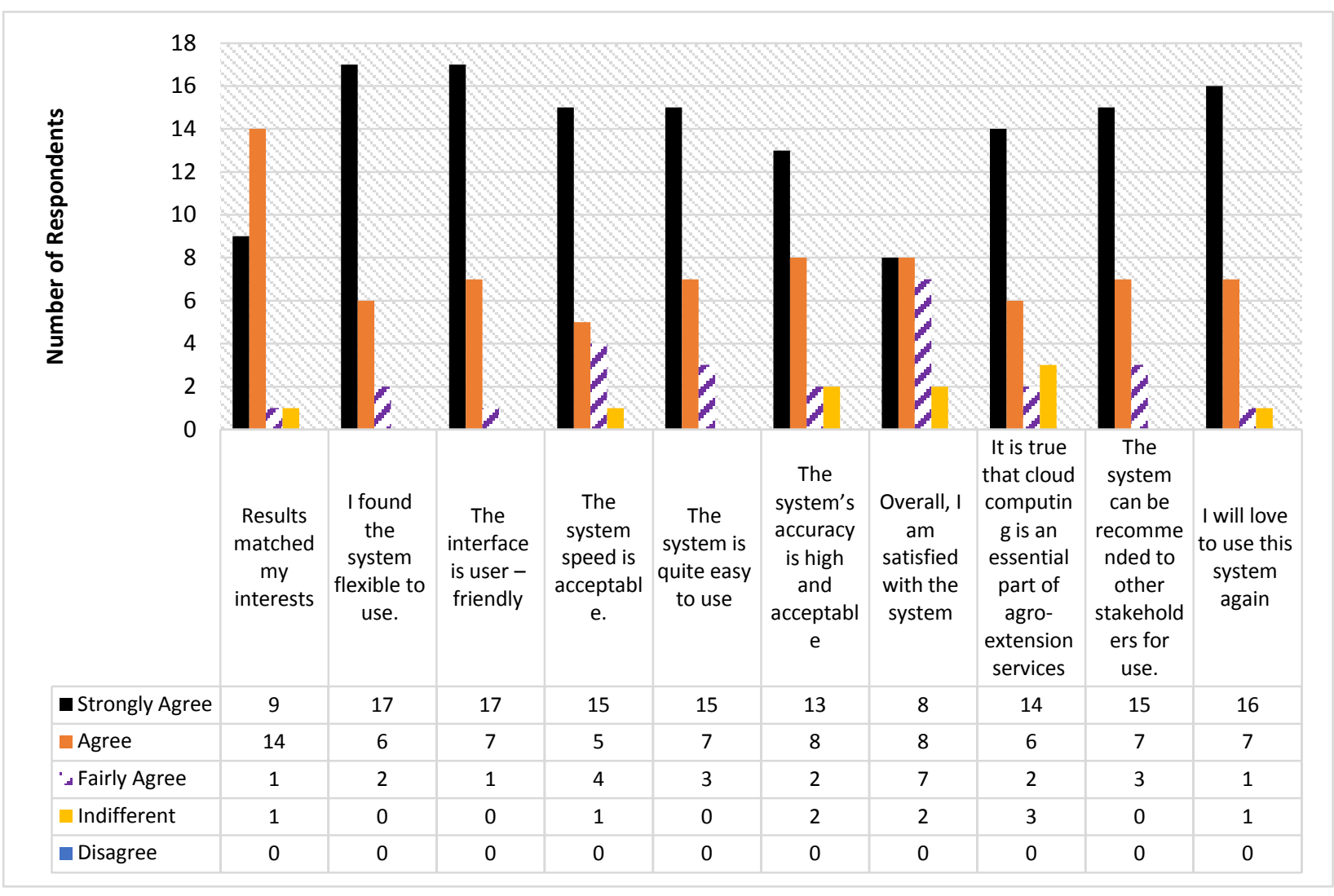

\section{Figure 4: Results of Users Evaluation}

From the results obtained from the analysis as shown in Figure 4, it was observed that, $36 \%$ of the users/respondents strongly agreed that the output of the system matched their original intentions, 56\% agreed, $4 \%$ fairly agreed and $4 \%$ were indifferent. This shows that, almost all the users (92\%) expressed satisfaction with the functionality or output of the proposed system. When it comes to the case of flexibility of the system for usage, it was observed that, about $68 \%$ of the users strongly-agreed that the system is flexible for usage, $24 \%$ agreed, and even $8 \%$ fairly-agreed. This shows that the system reacts well to users' demands. As it pertains userfriendliness of our proposed cloud-based agro-extension system, $68 \%$ of the users agreed strongly that the system is user-friendly, 28\% just agreed and $4 \%$ fairly agreed. The implication of this is that, users enjoy using the system, and derives satisfaction or aesthetics from the system. On the speed of the system, about $60 \%$ of the users strongly agreed that the system offers acceptable speed. About $20 \%$ agreed, $16 \%$ fairly agreed while $4 \%$ were indifferent about the speed of the system. Results also show that, $60 \%$ of the respondents strongly agreed that the system is easy to use, while $28 \%$ agreed, while $12 \%$ fairly agreed. This implies this system is easy to use. As far as accuracy is concerned, a large percentage of the users (52\%) strongly agreed that the system is accurate, $32 \%$ agreed, $8 \%$ fairly agreed, while about $8 \%$ were indifferent. The implication is that the proposed system is highly accurate. On whether the cloud computing paradigm is essential for agro-extension services, about 52\% strongly agreed, $24 \%$ agreed, while $8 \%$ of the respondents fairly agreed. Obviously from these, we can conclude that, cloud computing will go a long way in enhancing agro-extension services to farmers. This really agrees with the opinion expressed by researchers as highlighted in [19-20], in the sense that the use of cloud computing ameliorates so many aspects of human endeavors, and helps solve common issues that exist in existing traditional systems. In fact, about $88 \%$ of the respondents agreed that they can recommend the developed system for other users. Indeed, almost all the users/respondents stated that they would love to use the developed system over and over again.

Summarily, it is clear from the analysis of the responses obtained from the users that, this POI recommendation system performs excellently well as it provided recommendation according to the preferred choice of the users, such that a larger percentage would love to use the system again and also recommend to other people.

Discounted cumulative gain (DCG) is used for measuring ranking quality. Table 6 shows a user's recommendation and how the items are ranked in the database.

\section{CONCLUSION}

A Cloud-based agricultural information system that improves the effectiveness of extension programs and consequently facilitates the ease and effectiveness in the dissemination of information to farmers have been developed and presented in this paper. The adoption of this system will greatly benefit the extension workers, farmers, the nation as well as other developing economies. This is expected to improve agricultural productivity, increase food availability, and reduce poverty/hunger to a great extent, especially when the farmers utilize the provided information in the right way. It also ensures safety of extension workers during insurgency, banditry, or even infectious disease outbreaks, since the 
extension workers would be able to carry out their duties effectively and efficiently at their comfort. The major strengths of the system include consistent uptime, concurrency, automatic updates, flexibility, scalability and user-friendliness.

\section{ACKNOWLEDGMENTS}

Our thanks to the School of Computing, Federal University of Technology for providing the enabling environment for the study. Thanks also goes to the Ministry of Agriculture for their willingness to provide relevant information.

\section{REFERENCES}

[1] IFPR 2021. Food Security, a blog of the International Food Policy Research Institute. Food Security | IFPRI International Food Policy Research Institute.

[2] Kah, H. 2017. 'Boko Haram is Losing, But so is Food Production': Conflict and Food Insecurity in Nigeria and Cameroon. Africa Development / Afrique Et Development, 42(3), 177-196. Retrieved March 23, 2021, from http://www.jstor.org/stable/90018140.

[3] Otaha, I. J. 2013. Food Insecurity in Nigeria: Way Forward, An International Multidisciplinary Journal, Ethiopia Vol. 7 (4).

[4] Choudhary, S. K., Jadoun, R. S., Mandoriya H. L. 2016. Role of Cloud Computing Technology in Agriculture Fields. Computer Engineering and Intelligent systems, Vol. 7, No.3. ISSN 2222-1719.

[5] Sanga, C., Mlozi, M. Haug, R. Tumbo S. 2016. Mobile Learning Bridging the Gap in Agriculture Extension Service Delivery: Experiences from Sokoine University of Agriculture, Tanzania. International Journal of Education and Development Using Information and Communication Technology (IJEDICT) Vol. 12, Issue 2.

[6] Guo, L. Wang, W., Yang, Y., Sun, Z. 2015. Design and Implementation of Agro-technical Extension Information System Based on Cloud Storage. 7th International Conference on Computer and Computing Technologies in Agriculture (CCTA), Beijing, China. Pp.371-379, ff10.1007/978-3-642-54344-9_43ff. ffhal-01220939f.

[7] Oluwadare S. A., Gabriel A. J., Ogunride O. G. 2019. "Tabu-Genetic Algorithm-Based Model for Poultry Feed Formulation". International Journal of Sustainable Agricultural Research, Vol. 6, No. 2, pp. 94-109. DOI: 10.18488/journal.70.2019.62.94.109.

[8] Asfaw S, Shiferaw B, Simtowe F, Lipper L., 2012. Impact of modern agricultural technologies on smallholder welfare: evidence from Tanzania and Ethiopia. Food Policy. 2012; 37(3):283-95.
[9] Christoplos I, Kidd A. Guide for monitoring, evaluation and joint analyses of pluralistic extension support. Lindau: Neuchâtel Group; 2000.

[10] Food and Agriculture Organization (FAO) of the United Nations. Ethiopia Country Brief; 2010. Retrieved from www.fao.org/count ries/55528 /en/eth/.

[11] Bonye S. Z, Alfred K. B, Jasaw G. S. Promoting community-based extension agents as an alternative approach to formal agricultural extension service delivery in Northern Ghana. Asian J Agric Rural Dev. 2012;2(1):76-95

[12] Alemu A. E, Maetens M, Deckers J, Bauer H, Mathijs E. Impact of supply chain coordination on honey farmers' income in Tigray, Northern Ethiopia. Agric Food Econ. 2016; 4:9.

[13] Swanson B. E. Global review of good agricultural extension and advisory service practices. Rome: Food and Agriculture Organization of the United Nations; 2008.

[14] Barakabitze A. A., Fue K., Sanga C. 2017. The Use of Participatory Approaches in Developing ICT-Based Systems for Disseminating Agricultural Knowledge and Information for Farmers in Developing Countries: The Case of Tanzania. Electronic Journal of Information Systems in Developing Countries 78(8):1-23 DOI:10.1002/j.1681-4835.2017.tb00576.x

[15] Yaseen, M., Xu, S., Yu, W. and Hassan, S. 2016. Farmers' Access to Agricultural Information Sources: Evidences from Rural Pakistan. Journal of Agricultural Chemistry and Environment, 5, 12-19. doi: 10.4236/jacen.2016.51B003

[16] Boyaci, M., Yildiz O., 2016. An Overview of Agricultural Extension Services in Turkey. Bulgarian Journal of Agricultural Science. 2016:22(1)151-157.

[17] Rina D. C., 2017. The Cloud (The Future of Farming is in the Cloud). The future of farming is in the cloud (theweek.com).

[18] Arul K., 2020. The New Age: Cloud Computing in Agriculture Sectors. A white Paper of the W2S Solutions. (w2ssolutions.com).

[19] Gabriel A. J., Alese B.K., Adetunmbi A.O. and Adewale O.S. 2014; "Post-Quantum Crystography based Security Framework for Cloud Computing". Journal of Internet Technology and Secured Transactions (JITST), 3(4):344350. December 2014.

[20] Alabi O., Thompson A. F., Alese B. K., Gabriel A. J. 2020. Cloud Application Security using Hybrid Encryption. Journal of Communications. Foundation of Computer Science (FCS), NY, USA. 